\title{
Redistribution in a model of voting and campaign contributions
}

\author{
Filipe R. Campante $*$ \\ Harvard Kennedy School, Harvard University, 79 JFK St., Cambridge, MA 02138, United States
}

\section{A R T I C L E I N F O}

\section{Article history:}

Received 7 March 2010

Received in revised form 3 November 2010

Accepted 16 November 2010

Available online 7 December 2010

\section{JEL Classification:}

D31

D72

D78

Keywords:

Inequality

Redistribution

Political Participation

Voting

Elections

Campaign Contributions

Wealth Bias

\begin{abstract}
A B S T R A C T
I propose a framework in which individual political participation can take two distinct forms, voting and contributing resources to campaigns, in a context in which the negligible impact of any individual's actions on aggregate outcomes is fully recognized by all agents. I then use the framework to reassess the relationship between inequality and redistribution. The model shows that, even though each contribution has a negligible impact, the interaction between contributions and voting leads to an endogenous wealth bias in the political process, as the advantage of wealthier individuals in providing contributions encourages parties to move their platforms closer to those individuals' preferred positions. This mechanism can in turn explain why the standard median-voter-based prediction, that more inequality produces more redistribution, has received little empirical support: higher inequality endogenously shifts the political system further in favor of the rich. In equilibrium, there is a non-monotonic relationship in which redistribution is initially increasing but eventually decreasing in inequality. I present some empirical evidence supporting the framework, using data on campaign contributions from US presidential elections. In particular, inequality increases contributions to Republicans, but not to Democrats, as predicted by the model.
\end{abstract}

(C) 2010 Elsevier B.V. All rights reserved.

\section{Introduction}

Individual campaign contributions indisputably play a very important role in the political process - particularly in the US, where they make up 80 percent of campaign money. In fact, according to Ansolabehere et al. (2003), they also constitute the "marginal" dollar in campaigns, in the sense that whenever candidates face the greatest need to increase their funds, they tend to pursue individual contributions disproportionately. In addition, as argued by McCarty et al. (2006, ch. 5), the relative importance of individual contributions has increased over time, since donations by political action committees (PACs) have been increasingly restricted. ${ }^{1}$

While there is good reason to believe that these individual contributions should be a primary focus of research on the topic, the data reveal that the typical contribution is very small, around $\$ 115$. It is thus very unlikely that any contribution will be pivotal for the outcome, and as a result it is hardly appealing to think of individual contributions as buying favorable policies.

\footnotetext{
* Fax: + 16174957730 .

E-mail address: filipe_campante@harvard.edu.

1 This is likely to change, of course, with the recent Citizens United decision by the US Supreme Court.
}

It follows that strategic motives for contributing, as in "buying policy", are probably not the most appropriate way to think about these contributions. Besides the logical difficulty of explaining such small contributions as an investment, their very size is also a puzzle in this context: if so much is at stake in terms of the value of government policies, why are contributions so small? ${ }^{2}$

I propose a very simple model where individuals recognize that both their individual vote and donation will almost certainly not be decisive. As a result, voting and contribution decisions are treated symmetrically, both being essentially driven by consumption motives. Contributions cannot influence outcomes directly; in the model, as in reality, votes are what wins elections. Contributions, as in reality, can be used to influence voting behavior, by paying for things that increase the likelihood that one's supporters will outnumber those of competitors in the polls - "get out the vote" operations, registration drives, advertisements (Rosenstone and Hansen, 1996). While contributions are also used to influence potential voters' opinions, this is certainly not the whole story, and quite possibly not the main part of it. After all, parties, "like political scientists, know that mobilization

\footnotetext{
2 This is precisely the point Ansolabehere et al. (2003) emphasize, turning popular perception on its head: why is there so little money in US politics? In addition, they show that other empirical predictions of such an approach-e.g., contributions should grow as the role of government in the economy expands-are not borne out by the data. On this puzzle, see Chamon and Kaplan (2007).
} 
can increase participation, but it rarely changes preferences." (Rosenstone and Hansen, 1996, p. 163) ${ }^{3}$

To study the impact of this type of "small money" individual contribution, I apply these cornerstones to a model in the spirit of Meltzer and Richard (1981), where individuals differ in their levels of initial wealth, and where redistribution is determined as the outcome of an electoral political process. Quite importantly, no inherent distinction in terms of political behavior is assumed to separate individuals with different wealth levels. My model nests the standard median-voter framework as a special case, in which contributions do not affect voters' turnout. In the general case, however, the presence of campaign contributions leads to an endogenous "wealth bias" in the political process, as the agent whose preferences will prevail in equilibrium will be wealthier than the median. When contributions are important, parties are moved to adopt platforms to attract the wealthy, in order to generate more contributions that can then be used to increase the turnout of the party's supporters relative to its opponent's. The presence of individual contributions thus endogenously shifts the political system in favor of the rich, even though such contributions are not pivotal and do not affect policy or electoral outcomes directly.

Focusing on a decision on redistribution enables me to apply the model to the particularly interesting question of the relationship between inequality and redistribution, which has presented an important and long-standing puzzle. The standard answer from the theoretical literature dealing with the topic, provided precisely by Meltzer and Richard (1981), predicts a positive effect of inequality on the level of redistribution in equilibrium. ${ }^{4}$ This answer builds on a median-voter framework, in which higher levels of inequalitytypically measured by the difference between mean and median income-translate into a poorer decisive agent in the political arena, who will then demand more redistribution. In light of its elegance and intuitive appeal, this result has been widely used in the literature ever since. ${ }^{5}$ Nevertheless, the basic message that has emerged from the empirical literature on the topic is that "it has been hard to find compelling empirical evidence supporting the predictions" of the standard framework (Persson and Tabellini, 2000, p. 52). ${ }^{6}$

My model is able to make sense of this puzzle, while maintaining the tractability that is a major strength of the median-voter framework. An increase in inequality will enhance the advantage of the rich in providing contributions, by shifting resources in their favor, and this will in turn lead the parties to move their platforms closer to the preferred positions of wealthier individuals. As a result, the indifferent agent, whose preferences will be reflected in equilibrium, will now be someone at a higher percentile in the wealth distribution. More inequality will thus have an effect of strengthening the wealth bias in the political system. In the context of redistribution, this will work in the opposite direction of the usual median voter effect that was highlighted above. When this new "endogenous indifferent

\footnotetext{
${ }^{3}$ Kramer (1970) provides a classic empirical comparison between the "turnout" and "preference" effects of parties' mobilization efforts, concluding that the former is actually more important. Whichever is the most important, the indisputable fact is that parties focus a lot of their resources on mobilizing their supporters, an idea that is widespread in anecdotal accounts of US politics. Ansolabehere and Snyder (2000, p. 616-617) provide an empirical assessment of the relationship between party resources, their mobilization efforts, and voter turnout: state parties spend around 40 percent of their total resources on this mobilization. Since a large part of parties' expenses are administrative and overhead costs, this in fact constitutes a very large part of their available resources. For an evaluation of such efforts, see Bergan et al. (2005).

${ }^{4}$ Romer (1975) and Roberts (1977) contain some of the earlier insights within this approach.

${ }^{5}$ E.g. Alesina and Rodrik (1994), Persson and Tabellini (1994), Bolton and Roland (1997); see Persson and Tabellini (2000, ch. 6), for other examples.

6 This is what is summarized, for instance, by Bénabou's (1996) or Perotti's (1996) surveys of the cross-country evidence on the relationship between inequality and redistribution. For some studies providing favorable evidence, see for instance Meltzer and Richard (1983) or Milanovic (2000).
}

voter" effect is taken into account, a non-monotonic relationship emerges in equilibrium: redistribution will be decreasing in inequality when inequality is high, and increasing in inequality at the opposite end of the spectrum.

I also provide some evidence, in the context of the 2000 US presidential election, in support of the framework, when it comes to the patterns of campaign contributions.

The data suggest not only that the rich contribute disproportionately more than the poor, but also that inequality has a positive impact on contributions amassed by the relatively anti-redistribution (Republican) party, and a negative impact on those gathered by the relatively pro-redistribution (Democratic) party.

This paper is related to the literature on campaign contributions, which has pointed out that they can lead to departures from the median voter's preferred policies, and from those of non-contributors to the benefit of contributors (e.g. Austen-Smith, 1987; Grossman and Helpman, 1996; Prat, 2002; Coate, 2004; Roemer, 2006). While this literature focuses on campaign contributions by interest groups, modeled as an investment in "buying policy" or influencing outcomes, my model focuses on "small money" individual campaign contributions. My model thus reconciles the existence of a wealth bias with this more realistic context in which individual contributions, in symmetry with voting, are not pivotal. Finally, this literature has not focused directly on the puzzle regarding the link between inequality and redistribution. On the empirical side of the literature, this paper is closely related to Gimpel et al. (2006), who analyze contribution patterns to Republicans and Democrats across space.

Another direct connection of the paper is to the large literature attempting to deal with this puzzle. The first explanation, in that literature, is to consider the very natural possibility that political influence is related to economic resources: inequality could fail to lead to more redistribution because the rich are disproportionately influential in the political arena. ${ }^{7}$ Many papers thus assume that the decisive agent is someone wealthier than the median, in light of the evidence that political participation is positively correlated with wealth and income, which could easily lead to a reversion of the standard prediction (e.g. Bénabou, 2000). In fact, a literature in political science has also stressed the relationship between inequality and political participation (e.g. Rosenstone and Hansen, 1996; Lijphart, 1997), and pointed out informally that this link could help reconcile the evidence on inequality and redistribution (e.g. McCarty et al., 2006). My model goes beyond this approach by proposing a clear mechanism through which economic resources translate into political influence-namely individual campaign contributions and their impact on voting-and thus generating that positive relationship endogenously, instead of assuming it in reduced form. ${ }^{8}$

A second approach linking economic resources and political influence has made a more direct connection with lobbying and campaign contributions, as in models such as Rodríguez (2004). It shares with the literature on contributions the difficulty in dealing with the non-pivotal nature of individual contributions. Others have tried to deal with the empirical difficulties of the standard model by departing more sharply from it along many different lines (Roemer, 1998; Lee and Roemer, 2005; Iversen and Soskice, 2006, inter alia). A particularly related (and complementary) contribution is in Larcinese (2005), where information acquisition is the costly feature generating a wealth bias. Unlike this paper, none of these focuses on campaign contributions and its interaction with turnout decisions, which lets us

\footnotetext{
${ }^{7}$ Glaeser (2006) also raises the possibility that reverse causality may be behind the empirical observation, as redistribution may reduce inequality. Bénabou (2000) explores the possibility of multiple equilibria raised by the interaction of these two avenues of causality.

8 In fact, a closer look at the data reveals that simply assuming that the rich participate in politics more than the poor is not satisfactory: There is a lot of crosscountry variation in the relationship between income and participation, particularly voting, and in some countries such relationship is even negative (Verba et al., 1978).
} 


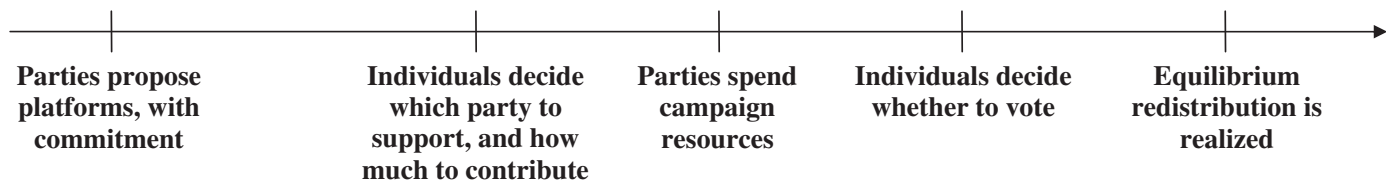

Fig. 1. Timeline,

have a clearer empirical counterpart to assess the impact of the proposed mechanism. In addition, precisely due to their being starker departures, they are not able to keep the tractability and the intuitive appeal that are major strengths of the standard framework.

The remainder of the paper is organized as follows: Section 2 presents the model; Section 3 states the main results and provides some empirical evidence; and Section 4 concludes.

\section{Inequality, campaign contributions and voting behavior: a simple model}

\subsection{Basic setup}

Let us consider a simple model that focuses on the interaction between inequality, different forms of political participation, and redistribution outcomes. I start with a population of individuals (potential voters) in a continuum of mass 1 . These individuals are identical, except for their initial wealth level, denoted by $w_{i}$, which is distributed according to some distribution $F(w)$. The only crucial assumption is that the distribution be skewed to the right, so that median wealth is smaller than mean wealth. However, for ease of exposition, I will assume a Pareto distribution. ${ }^{9}$ In addition to its analytical convenience, the Pareto distribution is usually thought to be a good approximation of the high range of actual wealth and income distributions (e.g. Levy and Levy, 2003), which is where most of the action concerning campaign contributions is. ${ }^{10}$ The cdf of the wealth distribution is thus given by:

$F(w)=1-\left(\frac{w_{\min }}{w}\right)^{\frac{1}{\sigma}}$

where $w_{\min }$ is the location parameter (minimum level of wealth in the distribution) and $\sigma \in(0,1)$ is the shape parameter that parameterizes inequality: an increase in inequality is simply an increase in $\sigma$. (Since I am interested in changes in inequality keeping average income constant, and since the mean level of wealth, $\bar{w}$, is given by $\frac{1}{1-\sigma} w_{\min }$, changes in $\sigma$ will be accompanied by changes in $w_{\min }$ such that $\bar{w}$ remains constant. In other words, I set $w_{\min }=(1-\sigma) \bar{w}$, and point out the instances where the choice is material.) Note, in particular, that the limit case $\sigma=0$ corresponds to a situation of "perfect equality", where all individuals have the same wealth, and the other limit case $\sigma=1$ corresponds to the polar opposite in which a single individual (of measure zero) holds all the wealth in the economy.

In addition to the individuals, there are two parties competing in an election where the crucial decision is on redistribution. Each party will propose a given redistribution rate as its campaign platform and, in keeping with the Downsian tradition (Downs, 1957), they are able to commit to their proposed rate. There are two forms of political participation that individuals can undertake, namely voting and

\footnotetext{
9 The working paper version of the paper (Campante, 2007) extends the results for the case of a generic $F(w)$. I will point out the instances where the generic results need qualification.

${ }^{10}$ The Pareto distribution also yields a convenient parametrization of changes in inequality, with a one-to-one correspondence with the Gini coefficient that will be used in the empirical analysis and to other measures of inequality such as the difference between mean and median. This parametrization is useful because in this context one needs to specify more precisely what is meant by changes in inequality - unlike in the standard median-voter framework, the relative wealth of the median individual will no longer be sufficient.
}

contributing resources to the parties. Votes decide the political outcome, but parties can use campaign contributions in order to affect the behavior of voters. This is summarized by the timeline in Fig. 1 .

Individuals will thus make their decisions taking platforms as given, and parties will have chosen their platforms in anticipation of individuals' behavior and the resulting equilibrium.

\subsection{Individuals}

Individuals in the model have to decide whether to vote or not, how much to contribute, and, conditional on those decisions, which party to support.

I will consider a very simple model of voting, in which individuals turn out to vote if they are sufficiently mobilized. More specifically, each individual has a certain cost of voting $c_{i}$, which is uniformly distributed over the interval $[0,1]$, and a mobilization parameter $\gamma_{i} \in[0,1]$ that will depend on the parties' actions. She will choose to vote whenever mobilization is enough to meet the cost: $\gamma_{i}>c_{i}$. Note that this means that individuals recognize their negligible impact on final outcomes: voting is linked to a "consumption" motive that could be related to some personal satisfaction or sense of duty. Also, I will assume that the voting decision is orthogonal to the distribution of wealth, so that it is not imposed exogenously that richer individuals have an inherent tendency to vote relatively more than poorer individuals. This is meant to focus attention on the endogenous impact of campaign contributions.

A key distinctive feature of the model is the presence of individual campaign contributions, and in particular our basic premise that they are essentially symmetric to voting. In other words, individuals recognize their own contribution's negligible impact, and are thus driven by similar non-strategic, consumption motives. This is meant to capture the dynamics of individual campaign contributions, which are typically very small, as previously discussed.

In order to capture this non-strategic, consumption motive in its simplest form, I assume that individuals will contribute a fixed share, denoted by $\lambda$, of their initial wealth. ${ }^{11}$ In other words, if we denote contributions by individual $i$ as $z_{i}$, we posit:

$z_{i}=\lambda w_{i}$

This starkly simplified assumption is made to sharpen the focus on the key mechanism of the model, but a crucial aspect is that contributions are a normal good: wealthier individuals contribute more. This assumption is central to the paper's results, and is backed by substantial evidence that individual income as a predictor of the likelihood and size of contributions (e.g. Rosenstone and Hansen, 1996; Ansolabehere et al., 2003, inter alia). ${ }^{12}$

Two other assumptions are embedded in (2). First, contributions cannot be affected by political parties - essentially implying that parties' ability to obtain resources are not dependent on their preexisting resources, thus ruling out the "it takes money to make money" feedback. Second, it assumes that the decisions on whether to

\footnotetext{
11 The working paper version contains a more microfounded model,where only highly politically motivated individuals contribute, as consistent with the evidence, and where contributions come from a utility-maximization problem of the consumption value of contributing.

${ }^{12}$ In fact, there is a lot of evidence that contributions are actually a luxury good: richer individuals contribute a larger share of their income. This would reinforce the paper's main results, and the working paper version contains a detailed treatment of this case.
} 
contribute-as was the case for turnout-are independent of party platforms. This is done partly to keep consistency with the fact that individuals recognize the irrelevance of their decisions on outcomes, but also to keep analytical simplicity. I will later discuss the implications of relaxing both assumptions.

Once an individual $i$ has decided to vote and/or contribute, she will choose which party to favor sincerely, based on which decision will be best for her in equilibrium by bringing equilibrium taxes closer to her preferred rate. We denote this preferred redistribution rate by $\tau_{i}$. To keep the model as close as possible to the standard median-voter framework, redistribution is described by a linear tax on wealth, at rate $\tau$, with lump-sum transfers to all individuals and a convex cost of taxation, $\phi(\tau)$ - assumed to be quadratic for analytical simplicity, as in Bolton and Roland (1997): $\phi(\tau)=\frac{\tau^{2}}{2} \bar{w}$. Each individual will want to maximize her disposable wealth, $w_{i}^{d}=(1-\tau) w_{i}+T$, with $T=\tau \bar{W}-\phi(\tau)$. Individual $i$ 's preferred tax rate is thus ${ }^{13}$ :

$\tau_{i}= \begin{cases}1-\frac{w_{i}}{\bar{w}} & , \text { if } w_{i}<\bar{w} \\ 0, & \text { otherwise }\end{cases}$

The result is quite intuitive: wealthier individuals will prefer lower tax rates, implying less redistribution. In particular, anyone whose wealth is above the mean level will prefer that there be no redistribution whatsoever.

\subsection{Parties}

The next step is to describe the positions of the parties with respect to redistribution, and their use of campaign money. I am primarily interested in a world in which there is disagreement between parties with respect to redistribution, so I assume that parties are policyoriented - i.e. they care about the equilibrium level of redistribution. For simplicity, let us ignore any pure office-seeking component to the parties' motivation. ${ }^{14}$ Party $j$ 's utility is described by:

$V_{j}\left(\tau_{j}, \tau_{-j} ; \hat{\tau}_{j}\right)=v\left(\tau\left(\tau_{j}, \tau_{-j}\right), \hat{\tau}_{j}\right)$

where $\tau_{j}$ is the rate proposed by Party $j, \tau$ is equilibrium redistribution (a function of the parties' platforms), and $\hat{\tau}_{j}$ is Party $j$ 's ideal rate of redistribution. The maintained assumptions are that $v(\cdot)$ is decreasing in the absolute value of $\tau-\hat{\tau}_{j}$, and concave. I also set $\hat{\tau}_{R}<\hat{\tau}_{D}$ : Party $R$ wants strictly less redistribution than Party $D$.

How is equilibrium redistribution determined? I draw upon Alesina and Rosenthal (1995) in postulating the following "nonmajoritarian" approach:

$\tau=\frac{\pi_{D} \tau_{D}+\pi_{R} \tau_{R}}{\pi_{D}+\pi_{R}}$

where $\pi_{j}$ is the number of votes obtained by Party $j$, which is also a function of the parties' platforms. In words, equilibrium redistribution is given by a convex combination of the preferred rates of each party, where the weights are given by the number of votes the party obtains: each party influences equilibrium policy according to its electoral strength. This assumption rules out the discontinuities that emerge from a "winner-take-all" setup in which the party that gets the most

\footnotetext{
13 One could assume in principle that wealthier individuals would be in favor of a negative tax rate, i.e. a linear income subsidy financed by a lump-sum tax. I believe this possibility is not very interesting empirically, so I leave it out in what follows.

14 The main results of the paper still hold with office-seeking parties, as discussed in the working paper version. Since this complicates the proofs withoutadding insight, 1 choose to consider the simplified case.
}

votes manages to impose its preferred policies, thus keeping the model analytically simple without otherwise affecting the results. ${ }^{15}$

This brings us to the role of campaign contributions. Eq. (5) makes clear that what matters for election outcomes is the amount of votes that each party obtains. I assume that parties can use the money they collect in order to boost the turnout of their own supporters, i.e. to "mobilize its base". ${ }^{16}$ (I assume that parties are able to discern who their likely supporters are, since the individuals' preferences over the two parties depend only on their wealth, which is observable..$^{17}$ ) As argued before, parties focus a lot of their attention on making sure that voters who are likely to support them actually turn out to vote, and contributions matter to a large extent because they are used by parties to increase the likelihood of turnout by their supporters.

Specifically, I assume that the mobilization component behind individual political participation is a function of the amount of contributions collected by the party that targets the group of which the individual is a member. In other words, if $i$ is a member of party $j$ 's constituency and party $j$ spends $Z_{j}$ on mobilizing its constituency, then: $\gamma_{i}=\gamma\left(Z_{j}\right)$, where $\gamma^{\prime}(\cdot)>0 .{ }^{18}$ This means that if a party spends more money, its potential supporters will be more mobilized, and hence more likely to turn out to vote. I also assume that $\gamma^{\prime \prime}(\cdot)<0$, implying that there are decreasing returns to the investment of campaign resources, and denote $\gamma(0)=\epsilon>0$.

\section{Main results}

\subsection{Equilibrium}

Let us start by characterizing the behavior of voters. Consider an equilibrium in which Party $j$ receives $\pi_{j}$ votes with corresponding platform $\tau_{j}$. In light of (5), individuals whose preferred rate is above $\tau$ will vote for the party with the highest proposed rate, as increasing its share of votes will move the equilibrium rate closer to the individual's ideal. Let us denote by $p^{*}$ the percentile at which the individual is indifferent between the two parties. This "indifferent" percentile will of course be the one whose preferred tax rate is exactly the equilibrium rate. Using (3), (5), this means $1-\frac{w_{p}{ }^{*}}{\bar{w}}=\frac{\pi_{D} \tau_{D}+\pi_{R} \tau_{R}}{\pi_{D}+\pi_{R}}$. Using the distributional assumption (1), we have $w_{p^{*}}=(1-\sigma)\left(1-p^{*}\right)^{-\sigma} \bar{w}$, and we can thus characterize $p^{*}$ as:

$p^{*}=1-\left[\frac{(1-\sigma)\left(\pi_{D}+\pi_{R}\right)}{\pi_{D}\left(1-\tau_{D}\right)+\pi_{R}\left(1-\tau_{R}\right)}\right] \frac{1}{\sigma}$.

Every individual below this percentile will support the party who proposes highest tax rate, whereas those above it will throw their support behind the other party. Let us denote the high-tax party as

\footnotetext{
${ }^{15}$ More precisely, as discussed in Alesina and Rosenthal (1995, p. 27), a "winnertake-all" assumption would generate policy convergence, since we are in a setup without uncertainty about voters' preferences. This would be unappealing in a context where I want to be able to differentiate between parties. It is nevertheless possible to extend the model to consider the "winner-take-all" case in the context of a probabilistic voting setup. (An extension in this direction is available upon request.) The basic results still hold, provided that parties are able to target their campaign spending, at least to some extent, on individuals that are more likely to support them; otherwise, there would be no point in spending at all (since in our model spending is all about mobilization, and not about changing voters' preferences). Later in the paper, as the results are presented, I will return to the intuition behind such extension.

16 Other approaches to contributions in the literature focus on its role in providing information or pure advertisement, which would affect individuals' preferences over candidates. See for instance Austen-Smith (1987), Grossman and Helpman (1996), Prat (2002), Coate (2004).

17 The assumption that parties are able to target their potential supporters is crucial for our results, although the particular feature that they can do so perfectly can be removed and is added just for simplicity. For evidence on howparties and politicians target their campaign spending, see for instance the survey by Gerber (2004).

18 Note that the possibility that contributions are used to interfere with the turnout of the opponent's supporters is equivalent: Given the parties' preferences, increasing the turnout of one's supporters and decreasing that of the opponent's are equivalent from the parties' standpoint.
} 
Party $j$, and let the other party be Party $-j$. Because individuals contribute a fixed fraction of their income, $\lambda$, it follows that the contributions obtained by each party are equal to:

$Z_{j}=\lambda\left(1-\left(1-p^{*}\right)^{1-\sigma}\right) \bar{w}$

$Z_{-j}=\lambda\left(1-p^{*}\right)^{1-\sigma} \bar{w}$

Given these contribution totals, we have the following values for the number of votes each party obtains, once again using the uniformity of $c_{i}$ :

$\pi_{j}=\gamma\left(\lambda\left(1-\left(1-p^{*}\right)^{1-\sigma}\right) \bar{w}\right) p^{*}$

$\pi_{-j}=\gamma\left(\lambda\left(1-p^{*}\right)^{1-\sigma} \bar{w}\right)\left(1-p^{*}\right)$

We can first establish two very intuitive points. First, the equilibrium tax rate must be between $\hat{\tau}_{R}$ and $\hat{\tau}_{D}$, since if that were not the case both parties would have an incentive to simultaneously increase or decrease their proposed rates, respectively. Second, in equilibrium we must have $\tau_{D} \geq \tau_{R}$ : Party $D$, the pro-redistributive party, will propose a higher tax rate in its platform. After all, if we had $\tau_{R}>\tau_{D}$, then Party $R$ could have a direct effect in reducing $p^{*}$, from (6). This would reduce contributions to Party $R$ itself, since it would play the role of Party $-j$ in this case, and thus reduce $\pi_{R}$ and increase $\pi_{D}$. But all of this would be a good outcome for Party $R$, as it would imply lower redistribution, in accordance with the party's goal. In sum, (7) and (9) refer to Party $D$, which is supported by the relatively poor individuals below the indifference percentile, while (8) and (10) describe the equilibrium outcomes of Party $R$.

Let us focus our attention on interior equilibria, where $\hat{\tau}_{R}<\tau<\hat{\tau}_{D}$. These are the more interesting equilibria, of course, since they are not determined purely by the arbitrary party preference parameters. We can state the following:

Lemma 1. In an interior equilibrium, $\pi_{D}=\pi_{R}$ : parties obtain the same number of votes.

\section{Proof. See Appendix.}

The intuition for this result is as follows: in an interior equilibrium, both parties would ideally want to change the equilibrium tax rate. For this to be an equilibrium, it must be that any change in platforms would have no impact on that equilibrium tax rate, as the impact on the number of votes would exactly cancel out the purported change. That is only possible if both parties are equally strong. In other words, we have an intuition that is similar to the logic of the median voter theorem, or the Calvert (1985) result of convergence with policymotivated parties: parties will split the distribution of actual voters right down the middle - otherwise one of the parties could improve its position.

The key difference, of course, is that here the median voter is not necessarily the median agent, but rather the agent at the $p^{*}$ percentile. This $p^{*}$ will be determined endogenously. The lemma implies that (6) can be rewritten as:

$p^{*}=1-\left[\frac{2(1-\sigma)}{2-\left(\tau_{D}+\tau_{R}\right)}\right] \frac{1}{\sigma}$

This in turn, along with (9) and (10), means that we can now characterize the interior equilibria of the model. To sharpen our focus on these equilibria, it is convenient to let $\hat{\tau}_{R}=0$ (i.e. Party $R$ aligns with the richest individuals) and $\hat{\tau}_{D}=\sigma$ (i.e. Party $D$ aligns with the poorest individuals) - so that we have the widest range for possible

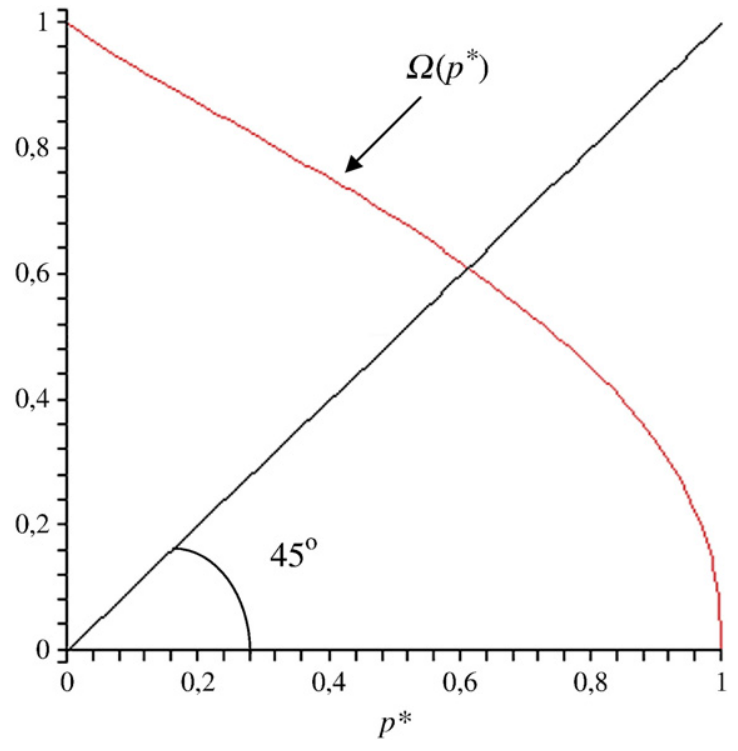

Fig. 2. Equilibrium $p^{*}$.

interior equilibria without restricting them with arbitrary parameters. In that case we can state:

Proposition 1 (Equilibrium). An interior equilibrium exists, and it will be characterized by a unique $\left(p^{*}, \tau\right)$ such that:

$$
\begin{aligned}
& p^{*}=\frac{\gamma\left(Z_{R}\right)}{\gamma\left(Z_{R}\right)+\gamma\left(Z_{D}\right)} \equiv \Omega\left(p^{*}\right) \\
& \tau=\max \left\{1-(1-\sigma)\left(1-p^{*}\right)^{-\sigma}, 0\right\} .
\end{aligned}
$$

\section{Proof. See Appendix.}

Proposition 1 can be understood with the help of Fig. 2, which plots the function $\Omega\left(p^{*}\right)$, corresponding to the RHS of Eq. (12). This function describes Party R's relative ability to get a given set of potential supporters to actually turn out and vote. On the other hand, $p^{*}$ is the relative size of Party $D$ 's base of potential supporters. In equilibrium, these two have to exactly balance each other out, so the equilibrium $p^{*}$ is given by a fixed point of $\Omega(\cdot)$. Proposition 1 establishes that this fixed point exists, due to continuity, and is unique, due to monotonicity, which in turn is guaranteed because an increase in $p^{*}$ means that the number of potential supporters (and thus contributors) of Party $R$ gets smaller; for a given wealth distribution, this means fewer resources, and a reduced ability to turn out the vote. ${ }^{19}$

Eq. (13) then describes the equilibrium redistribution rate that corresponds to this $p^{*}$. Note in particular, from (3), that this rate is precisely the one that is desired by the $p^{*}$ agent in the distribution. If the value of $p^{*}$ yielded by (12) happens to be at or above the percentile at which an individual holds exactly $\bar{w}$, which is defined as $\bar{p}(\sigma) \equiv 1-(1-\sigma)^{\frac{1}{\sigma}}$, then the equilibrium tax rate will be equal to zero, since negative tax rates have been ruled out.

\footnotetext{
19 The uniqueness of the equilibrium hinges on the assumption that $\lambda_{i}$ is constant with respect to the announced platform. If instead we have a situation where, for instance, a contributor will donate a greater share of her income if the party's position is closer to her preferred policy, the possibility of multiple equilibria arises. (These results are available upon request.) The intuition is that, under such circumstances, increasing its pool of potential supporters may not be in a party's interest, as the policy change required for that may alienate its core supporters so much that it ends up depressing the party's total contributions and turnout. If $\lambda_{i}$ is not too sensitive, we still have uniqueness, and the results follow through.
} 


\subsection{The effects of inequality}

Now it is possible to analyze the impact of inequality on the endogenous variables, namely turnout, contributions, and redistribution. The first crucial result can be stated as:

Proposition 2 (Median voter). If $\gamma^{\prime}(\cdot)=0$, that is contributions do not affect turnout, then:

1. $p^{*}=\frac{1}{2}$ : the "indifferent" percentile is the median.

2. $\frac{\partial \tau}{\partial \sigma}>0$ : equilibrium redistribution increases with inequality.

Proof. See Appendix.

This proposition spells out the standard median-voter-based result as a special case of my model. If the channel through which contributions affect turnout is shut down, then the standard logic goes through. When contributions do affect turnout, however, another channel opens up through which inequality can affect the political process. The first consequence of this can be stated as follows:

Proposition 3 (Wealth bias). If $\gamma^{\prime}(\cdot)>0$, then $p^{*}>\frac{1}{2}$ : The agent in the indifferent percentile is wealthier than the median agent.

Proof. See Appendix.

This proposition establishes that introducing a link between campaign contributions and turnout endogenously generates a wealth bias in the political process: the indifferent agent, whose preferences will be enacted in equilibrium, will be wealthier than the median. ${ }^{20}$ The intuition behind this result is quite transparent: once there is inequality in the distribution of wealth, the advantage of wealthier individuals in providing contributions enables Party $R$ to move its platform closer to its bliss point, since the contributions allow it to obtain a relatively higher turnout despite the smaller base of potential supporters. Conversely, Party $D$ has to follow the move to the right so as to compensate its disadvantage in gathering campaign resources with a larger number of potential supporters. ${ }^{21}$ Quite importantly, this bias does not require any inherent link between wealth and one's propensity to participate in politics.

This result leads us into the following ${ }^{22}$ :

Proposition 4 (Median voter revisited: non-monotonicity). If $\gamma^{\prime}(\cdot)>$ $0, \lim _{Z \rightarrow \infty}\left(Z \gamma^{\prime}(Z)\right)=\infty$ (i.e. the marginal effect of campaign spending does not vanish too rapidly), and $\epsilon$ is small (i.e. mobilization is small in the absence of campaign spending), then there exists $\bar{\sigma}>0$ such that $\sigma<\bar{\sigma} \Rightarrow \frac{\partial \tau}{\partial \sigma}>0$ and $\sigma>\bar{\sigma} \Rightarrow \frac{\partial \tau}{\partial \sigma}<0$ : equilibrium redistribution increases

\footnotetext{
20 This wealth bias is similar to that in Roemer (2006).

${ }^{21}$ Here it is possible to see why the model's results still hold if we replace (5) by a "winner-take-all", probabilistic voting specification. In the basic probabilistic voting model (e.g. Persson and Tabellini, 2000, p. 34), when parties choose their platforms they will give more weight to more "responsive" individuals, i.e. those who are more likely to reward a given change in platform. As we introduce campaign contributions, wealthier individuals will endogenously emerge as more responsive, since their support is amplified by their ability to contribute resources. Note also that the results still hold if parties are office-seekers (and hence regardless of whether there is policy convergence, in the sense of $\tau_{D}=\tau_{R}$ ): first, Lemma 1 still holds due to standard Downsian arguments; second, the need for obtaining campaign resources to enhance their likelihood of reaching office leads the parties to move their platforms closer to the preferences of wealthier individuals, who can provide them with more of these resources..

${ }^{22}$ For the case of a generic wealth distribution $F(w)$, this result has to be modified. Specifically, it is not possible to fully characterize the impact of inequality on equilibrium redistribution, since a generic distribution does not let us conceptualize what a change in inequality means in general. Nevertheless, the broad point about non-monotonicity can be established, in that the effect of inequality on redistribution is positive both when inequality is increased from perfect equality, and when it is decreased from perfect inequality. (This is available upon request.)
}

with inequality if inequality is relatively small, and it decreases with inequality if inequality is relatively large.

\section{Proof. See Appendix.}

The impact of inequality on redistribution is driven by the interaction of two effects. First, we have what can be termed an "indifferent voter's preference" effect, corresponding to the direct effect of $\sigma$ in (13), keeping $p^{*}$ constant. This is the impact of inequality on the level of redistribution desired by a given decisive agent. The Appendix shows that this effect is proportional to $\left(1+(1-\sigma) \log \left(1-p^{*}\right)\right)$, and from this expression we can see that the effect, which is behind Proposition 2 , is now more subtle precisely because of the endogenous wealth bias uncovered by Proposition 3: if $p^{*}$ is sufficiently large, it could be the case that the effect is negative. In words, the indifferent agent now may be wealthy enough that an increase in inequality can lead her to desire less redistribution.

Second, we also have an "endogenous indifferent voter" effect, which stems from the fact that the identity of the decisive agent is now endogenous and varies with inequality. The Appendix shows that this effect is captured by $-\frac{(1-\sigma) \sigma}{\left(1-p^{*}\right)} \frac{\partial p^{*}}{\partial \sigma}$, which is negative because $\frac{\partial p^{*}}{\partial \sigma}>0$ : an increase in inequality moves the indifferent vote to a higher percentile. (This can be seen graphically in Fig. 3.) The intuition is simple: higher inequality means that relatively rich individuals become richer, and relatively poor individuals become poorer. This amplifies the advantage of wealthier individuals in generating contribution revenues that can be translated into more votes, and increases the wealth bias identified in Proposition 3.

Put together, the "endogenous indifferent voter" effect and the possibility of changing the direction of the "indifferent voter's preference" effect can lead to the standard prediction being turned on its head: higher inequality may lead to less redistribution.

The proposition also elaborates on this possibility more precisely, by showing that in equilibrium there will be a non-monotonic relationship between inequality and redistribution. In order to understand the intuition behind this result, consider a situation of perfect equality $(\sigma=0)$, in which all agents possess the same wealth. In such a situation, the indifferent agent is the median, since there is no incentive for the parties to deviate from this position so as to increase their level of contributions, and redistribution is obviously a moot point. A small increase in inequality from this initial point creates a large mass of

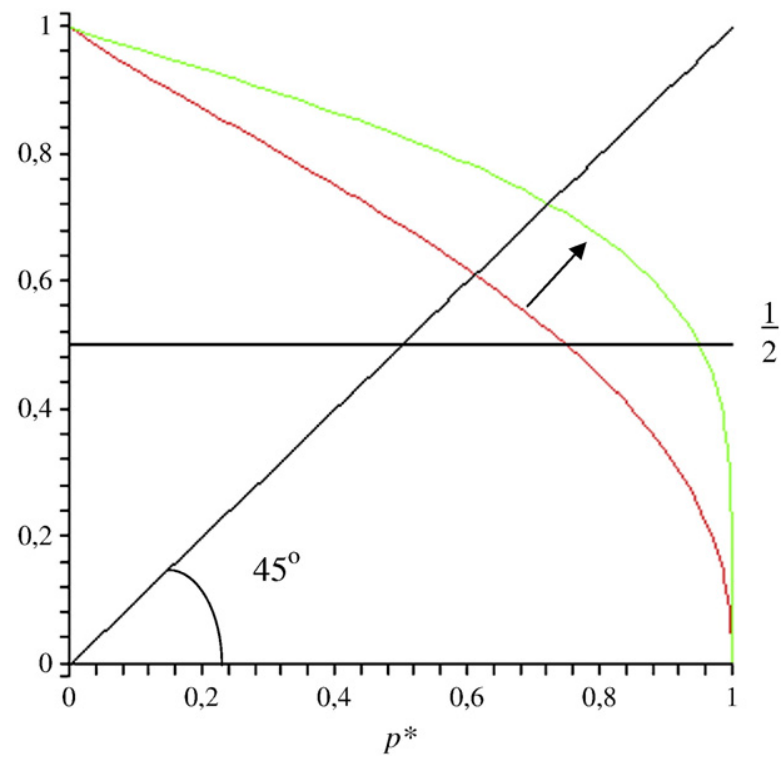

Fig. 3. "Endogenous Indifferent Voter" effect. 
individuals who are poorer than the mean, and hence in favor of redistribution, and they have almost the same wealth (and hence ability to contribute) as those few individuals who are now wealthier. This will surely lead to an equilibrium with more redistribution.

As inequality increases, however, the relatively wealthy start having a large advantage in providing parties with resources, strengthening the parties' incentive to move their platform away from redistribution. At some point, additional increases in inequality will lead to the indifferent agent being one who is wealthy enough to actually demand less redistribution, reverting the standard prediction. That this has to be the case can be seen by considering the situation of perfect inequality $(\sigma=1)$, where all the wealth in the economy belongs to a single individual (of measure zero). Such an individual concentrates in essence all the political power, since the turnout of the relatively poor will be tiny, and she wants no redistribution at all; any decrease in inequality will shift some political power to relatively poorer agents, who will definitely want some redistribution. As a result, the standard prediction will hold when inequality is relatively low, but will be reversed when inequality is sufficiently high. (Note that this non-monotonicity result will hold if the effect of obtaining additional contributions does not vanish too rapidly. If it does, contributions quickly cease to matter, and Proposition 2 shows that the standard result will thus prevail.)

Interestingly, this non-monotonicity result is the opposite of what is obtained by Bénabou (2000): in his framework, support for redistribution decreases with inequality for low levels of the latter, and eventually increases. The key differences are that, in that paper, a wealth bias in the political process is exogenously assumed, and redistribution also helps to pay for efficiency-enhancing expenditures. This is what lies behind his non-monotonicity result, as the coalition supporting redistribution will fluctuate with inequality. However, my framework shows that the conclusions are very different when the decisive agent in the political process is endogenously determined, since this endogenous mechanism operates in the opposite direction. ${ }^{23}$

The mechanism that the model highlights also translates into a specific prediction concerning the behavior of the amounts of contributions gathered by Party $D$ and Party $R$. This can be summarized in the following:

Corollary 1. Under the same conditions of Proposition $4, \frac{\partial Z_{R}}{\partial \sigma}>0$ and $\frac{\partial Z_{D}}{\partial \sigma}<0$ : inequality increases the amount of contributions collected by Party $R$, and decreases the amount collected by Party $D$.

Proof. See Appendix.

This is a central prediction of this framework. It is crucial for the results that changes in inequality affect the amount that is contributed by the relatively poor and the relatively wealthy, and that this effect alters the incentives of parties in seeking contributions. In equilibrium, it has to be the case that an increase in inequality will increase the contributions gathered by the anti-redistribution party and decrease the resources available to the pro-redistribution party, even though the number of potential supporters goes down for the former and up for the latter.

\subsection{Some empirical evidence}

We can actually provide some empirical evidence in favor of the model when it comes to individual campaign contribution patterns, looking at data from the United States. I use two complementary sources of information: the official data on contributions given to presidential candidate committees and to party committees, from the Federal Election Commission (FEC), and the 2006 Cooperative Congressional Election Survey (CCES) (Ansolabehere, 2007). The FEC data gives us the

\footnotetext{
${ }^{23}$ A non-monotonicity result that is similar in spirit to mine is in Mattozzi (2005) through a very different mechanism, linked to the interaction between policy uncertainty and unequal access to insurance markets.
}

universe of individual contributions above the minimum of $\$ 200$ lets us look at the pattern of contributions amassed by the two main parties, but has little information on the demographics of contributors at the individual level. The CCES is a survey that asks a large sample of individuals (36,500 in total) whether they have contributed money to politics, and how much. In contrast with the FEC data, it is not limited to contributions above $\$ 200$ and, most importantly, it has information on the individual characteristics. However, it does not trace contributions to their destination. The two put together allow for a tentative look at some of our assumptions and predictions.

To make use of the FEC data, in the absence of individual characteristics, we must use variation at a more aggregate level. I choose to aggregate the data at the county level, which yields a reasonably large sample, and that it lends itself to a smooth merging of the Census data from which many of the independent variables come. ${ }^{24}$ The use of county-level variation requires some discussion. First of all, since we are within the context of a federal election, it means that we cannot analyze our main prediction on redistribution policy outcomes. For that, we would require that the source of variation and the level at which policy is chosen were the same, which is not the case with the available data.

Second, and quite importantly, we must clarify why inequality at the county level would have any bearing with regard to our framework. The key point is that an increase in inequality plays two roles in the theory. By shifting resources across individuals, it affects each individual's preferences regarding redistribution. In addition, it also affects the amount of resources each one is willing to contribute, for given preferences. The income distribution at the county level should not matter directly in determining an individual's preferences regarding the policy platforms, so the first effect is not present. Nevertheless, it does affect the second channel. If we compare two counties, controlling for a number of characteristics that should affect the amount of contributions and the party they tend to favor-income and education levels, racial and religious composition, political factors-one would expect that, in the more unequal one, relatively rich individuals will hold relatively more of the wealth. This will affect the pattern of contributions, and will do so along the same lines as in the general model.

This is particularly true with respect to the impact of inequality on the contributions going to each party, as described by Corollary 1 . To see this more clearly, I assume for simplicity that each county $k$ also has its wealth distributed according to a (county-specific) Pareto distribution: $F_{k}(w)=1-\left(\frac{w_{k, m i n}}{w}\right)^{\frac{1}{\sigma_{k}}} \cdot{ }^{25}$ It is easy to see that this implies that the contributions that the model predicts for each party in that county will be given by $Z_{R}^{k}=\lambda \frac{1}{1-\sigma_{k}}\left(\frac{w_{k, \min }}{w_{p^{\star}}}\right)^{\frac{1}{\sigma_{k}}} w_{p^{\star}}$ and $Z_{D}^{k}=\lambda \frac{w_{k, \min }}{1-\sigma_{k}}-\lambda Z_{R}^{k}$, where $w_{p^{\star}}$ is defined as the wealth of the $p^{\star}$ percentile as given by the national distribution. The aforementioned first channel would operate exactly through changes in $w_{p^{*}}$, and is thus shut down; however, the expressions show that the contributions to each party would still be affected by county-level inequality $\left(\sigma_{k}\right)$, which affects the wealth held by different individuals. In the Appendix, I show that, as long as the county has supporters of both parties $\left(w_{k, \min }<w_{p^{*}}\right)$, it follows that an increase in inequality will increase the contributions collected by Party $R$, and have a negative effect on the contributions collected by Party $D$ (as long as average wealth is not too large). ${ }^{26}$ In other words, countylevel inequality confirms the message from Corollary 1.

\footnotetext{
24 The use of Census variables is the main reason I focus on the 2000 election cycle, for a Census year such as 2000 provides a more appropriate match between the different variables along the time dimension. The CCES data, in contrast, refers to 2005-06.

${ }^{25}$ I thank an anonymous referee for suggesting this presentation.

${ }^{26}$ The Appendix shows that there is some ambiguity in the latter effect, to the extent that changes in inequality affect average wealth. Alternatively, if we look at changes in the distribution that keep mean wealth constant, some ambiguity is introduced into the effect of inequality on Party R's contributions, while Party D's are unambiguous. Either way, this is only important if average wealth is very large.
} 
Table 1

Inequality and campaign contributions.

\begin{tabular}{|c|c|c|c|c|}
\hline & (1) & $(2)$ & (3) & (4) \\
\hline & Contribution & Amount & Amount & Amount \\
\hline & (Probit) & (Conditional) & (Republicans) & (Democrats) \\
\hline Individual income & $\begin{array}{l}0.025 \\
{[0.001]^{* * *}}\end{array}$ & $\begin{array}{l}35.673 \\
{[6.543]^{* * *}}\end{array}$ & & \\
\hline Income inequality & & & $\begin{array}{l}0.603 \\
{[0.204]^{* * *}}\end{array}$ & $\begin{array}{l}-0.103 \\
{[0.135]}\end{array}$ \\
\hline (Log) County income & & & $\begin{array}{l}0.263 \\
{[0.042]^{* * *}}\end{array}$ & $\begin{array}{l}0.124 \\
{[0.025]^{* * *}}\end{array}$ \\
\hline Observations & 24827 & 6471 & 2880 & 2880 \\
\hline R-squared & 0.100 & 0.028 & 0.387 & 0.442 \\
\hline
\end{tabular}

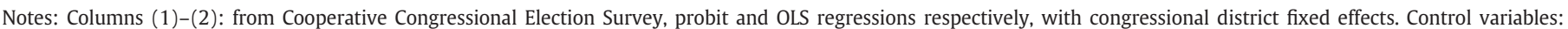
education, age, employment status, gender, race.

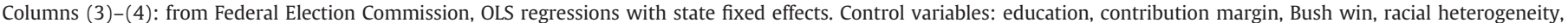
religious heterogeneity.

Robust standard errors in brackets.

* Significant at 10\%; ** significant at 5\%; ${ }^{* * *}$ significant at $1 \%$.

US politics is a good context in which to check the effect of the type of campaign contributions the model focuses on. A large portion of campaign money comes from individual contributions and these contributions are typically very small and would hardly be decisive in the context of a presidential election. Specifically, in the FEC data, the median direct contribution (which excludes contributions mediated by other committees and as such was subject to legal limits) is $\$ 500$, and less than five percent of them are above $\$ 2,000$; the mean is around $\$ 800 .{ }^{27}$ These amounts are hardly decisive in the context of a presidential election, but they are overestimates, since the data are restricted to contributions above $\$ 200$. In the CCES data, the mean is just $\$ 300$ (among those who contribute), and $90 \%$ of the contributions are below $\$ 500$. Nevertheless, when put together they amount to a very significant figure, in excess of $\$ 1$ billion when total contributions are considered. They are also very widespread: in the CCES, just under $30 \%$ of respondents had donated some money. This suggests that the mechanism highlighted by the model is potentially very important. igns in the 1999-2000 election cycle (Ansolabehere et al., 2003).

Table 1 summarizes the results. Columns (1)-(2) use the CCES individual-level data to establish the evidence for our basic assumption, that richer individuals contribute more than poorer individuals. Controlling for a number of individual demographic characteristics (education, race, gender, age, and employment status), plus congressional district fixed effects, Column (1) shows that richer individuals have a higher probability to contribute, in a probit regression (marginal effects reported). Moving up one discrete income category (which corresponds to an increase of roughly $\$ 10,000$ ) increases the probability of contributing by 2.5 percentage points - quite important if we keep in mind that around $30 \%$ of the sample donate money. Column (2) shows that, conditional on contributing, income increases the value that is donated. In sum, there is strong evidence that campaign contributions are a normal good, consistent with the stylized fact in the literature.

Columns (3) and (4) provide a more direct look at some of the model's predictions, as captured by Corollary 1 . They aggregate the FEC data, with the (log of) total contribution amounts (normalized by total voting age population) as the dependent variable. ${ }^{28}$ (All countylevel regressions include state fixed effects.) The results, broken down by party, are quite clear. Inequality has a strong positive effect on the amount of contributions directed to the Republican Party, the obvious

\footnotetext{
27 Quite interestingly, we see that total contributions are well below the individual contribution limits-in $2000, \$ 1,000$ for candidates and $\$ 20,000$ for parties-suggesting that such limits were typically not binding. Note that, in the 2000 election "soft money" could still be used by corporate or union donors essentially without limits.

${ }^{28}$ More precisely, I consider the log of one plus the amount of contributions, so that zero values are left in the sample. The results are qualitatively unchanged if such values are left out.
}

empirical counterpart of Party $R$, but it has a (weak) negative effect on the contributions raised by the Democratic Party. This is exactly in line with what is predicted by Corollary 1 . Note also that the effect of income on contributions is significantly higher for the Republican Party: wealthier counties contribute disproportionately more to the Republicans. This is also consistent with the mechanism highlighted by the theory.

In sum, some preliminary evidence suggests that inequality is indeed associated with shifting contributions from the relatively proredistribution party to the anti-redistribution one. This could very well shift the political system towards the preferences of the relatively wealthy, as suggested by the theory.

\section{Concluding remarks}

I have proposed a framework where political participation takes two distinct forms-voting and contributing resources to campaignsin a context in which individuals recognize that their decisions are not pivotal for aggregate outcomes. In spite of this non-pivotal nature, and endogenous wealth bias emerges in the political process, as a result of the interaction between contributions and voting decisions. When applied to the context of the relationship between inequality and redistribution, the framework shows that such relationship becomes much more subtle than the simple logic of the standard median voter framework would suggest. In equilibrium, redistribution is nonmonotonic in inequality, increasing at first but eventually decreasing.

This framework also sheds light on a host of issues that, while outside the direct scope of this paper, still relate to its building blocks. One such issue has to do with the consequences of alternative forms of campaign funding. For instance, in the very active debate on campaign finance reform in the US, it is often mentioned that public funding would curtail the disproportionate influence of wealthier individuals and pressure groups on the electoral process. My model suggests that this would indeed be the case, but only if a total ban, or at least very stringent limits, on individual contributions were introduced as well. In fact, I can show that, unsurprisingly, the central results concerning the effect of inequality on redistribution are maintained as long as the contribution limits are not too restrictive. (These results are also available upon request.) In particular, what matters is not the limit in absolute terms, but rather in comparison with the share of income that individuals would be willing to contribute in the absence of limits. Since the latter is likely to be quite small-Ansolabehere et al. (2003) quote the figure of 0.04 percent of national income devoted to political campaigns in the US in 2000-the limits would probably have to be very stringent indeed.

More generally, the framework can be used to analyze other implications of this mechanism beyond the ones addressed in the 
paper. Any policy choice over which preferences vary systematically with individual wealth or income-say, if wealthier individuals have a stronger preference for protecting the environment, or for financing tertiary over primary education-can also be studied taking into account the role of contributions and the endogeneity of participation. In particular, the endogenous wealth bias should still be present in these other contexts. Topics on comparative politics, such as the redistributive consequences of majoritarian and proportional systems, can also be reassessed under these lenses, as their possibly different implications regarding the role of campaign contributions could translate into different policy outcomes. These are some issues I intend to consider in future work.

On the empirical side, one would like to bring policy outcomes into the picture, which, as stressed before, would require data on inequality, political variables, and policy outcomes to be obtained from the same level - local, state, or country. One could then test for many other predictions generated by the framework: how much of the cross-country differences in terms of inequality and redistribution can be explained, or if a greater role of campaign contributions is in fact associated with a stronger "right-wing" bias and with a stronger link between personal income and turnout. At a sub-national level, this raises issues of data availability, such as obtaining information on redistribution outcomes; at the cross-country level, it would require a careful consideration of institutional differences. These are also issues for future research.

\section{Acknowledgments}

I owe special thanks to Alberto Alesina, Andrei Shleifer, and Philippe Aghion for their many suggestions and overall guidance in this project, and to the co-editor Brian Knight and three anonymous referees for their very helpful input. I also thank Jim Alt, Daniel Carvalho, Raj Chetty, Davin Chor, Alexandre Debs, Quoc-Anh Do, James Foster, Jeffry Frieden, Bard Harstad, Navin Kartik, Michael Katz, Alessandro Lizzeri, Torsten Persson, Kartini Shastry, and Kenneth Shepsle for useful comments. Helpful comments from seminar participants at the NBER Political Economy Program meeting, the Economics and Government departments and the Kennedy School of Government at Harvard, EPGE-FGV, IIES, London Business School, PUC-Rio, Singapore Management University, UC Santa Cruz, UC San Diego, UW Madison, and Vanderbilt are also gratefully acknowledged. Last but not least, I thank Reza Baqir for kindly providing part of the data, and Jim Davis, from the Boston Census Research Data Center, for invaluable help with the data analysis. Needless to say, all remaining errors are my own.

\section{Appendix}

Proof of Lemma 1. Let us consider an interior equilibrium, in which $\hat{\tau}_{R}<\tau<\hat{\tau}_{D}$. If both parties are maximizing (4) with respect to $\tau_{j}$, while taking the other party's platform as given, we have the following FOC:

$\frac{\partial V_{j}}{\partial \tau_{j}}=\frac{\partial v\left(\tau, \hat{\tau}_{j}\right)}{\partial \tau} \frac{\partial \tau}{\partial \tau_{j}}=0$

From (5), it follows that:

$\frac{\partial \tau}{\partial \tau_{D}}=\frac{\pi_{D}}{\pi_{D}+\pi_{R}}+\frac{\left(\tau_{D}-\tau_{R}\right)\left(\pi_{R} \frac{\partial \pi_{D}}{\partial \tau_{D}}-\pi_{D} \frac{\partial \pi_{R}}{\partial \tau_{D}}\right)}{\left(\pi_{D}+\pi_{R}\right)^{2}}$ $\frac{\partial \tau}{\partial \tau_{R}}=\frac{\pi_{R}}{\pi_{D}+\pi_{R}}+\frac{\left(\tau_{D}-\tau_{R}\right)\left(\pi_{R} \frac{\partial \pi_{D}}{\partial \tau_{R}}-\pi_{D} \frac{\partial \pi_{R}}{\partial \tau_{R}}\right)}{\left(\pi_{D}+\pi_{R}\right)^{2}}$.

Note also that, given (9) and (10), we have:

$\frac{\partial \pi_{D}}{\partial \tau_{D}}=\frac{\partial \pi_{D}}{\partial \tau_{R}}=\frac{\partial p^{*}}{\partial \tau_{D}}\left[\gamma\left(Z_{D}\right)+\gamma^{\prime}\left(Z_{D}\right) \lambda \bar{w}(1-\sigma)\left(1-p^{*}\right)^{-\sigma} p^{*}\right]<0$

$\frac{\partial \pi_{R}}{\partial \tau_{R}}=\frac{\partial \pi_{R}}{\partial \tau_{D}}=-\frac{\partial p^{*}}{\partial \tau_{R}}\left[\gamma\left(Z_{R}\right)+\gamma^{\prime}\left(Z_{R}\right) \lambda \bar{w}(1-\sigma)\left(1-p^{*}\right)^{1-\sigma}\right]>0$

Now note that in an interior equilibrium the FOC requires that $\frac{\partial \tau}{\partial \tau_{D}}=\frac{\partial \tau}{\partial \tau_{R}}=0$, since $v\left(\tau, \hat{\tau}_{j}\right)$ is concave and maximized at $\tau=\hat{\tau}_{j}$. Combining (15), (16), (17) and (18), this implies $\pi_{D}=\pi_{R}$.

Note that there exists the possibility of corner equilibria. For instance, we could have $\tau=\hat{\tau}_{R}$, which Party $R$ would obviously find optimal, but with Party $D$ not having an incentive to increase $\tau_{D}$ because it would have no impact on $\tau$. (This would be true, as an illustration, in the trivial case with no inequality $(\sigma=0)$, as all individuals would prefer no taxes and Party $D$ would have no gain from proposing a higher tax rate.)

Proof of Proposition 1. Lemma 1 and (5) imply that in equilibrium we have $\tau=\frac{\tau_{D}+\tau_{R}}{2}$. Using this in (11) immediately implies that $p^{*}$ and $\tau$ are linked by Eq. (13): To any $p^{*}$ corresponds a unique $\tau$. In addition, Lemma 1 and Eqs. (9) and (10) imply that:

$$
\begin{aligned}
& \gamma\left(\lambda\left(1-p^{*}\right)^{1-\sigma} \bar{w}\right)\left(1-p^{*}\right)=\gamma\left(\lambda\left(1-\left(1-p^{*}\right)^{1-\sigma}\right) \bar{w}\right) p^{*} \Rightarrow \\
& \Rightarrow p^{*}=\frac{\gamma\left(\lambda\left(1-p^{*}\right)^{1-\sigma} \bar{w}\right)}{\gamma\left(\lambda\left(1-p^{*}\right)^{1-\sigma} \bar{w}\right)+\gamma\left(\lambda\left(1-\left(1-p^{*}\right)^{1-\sigma}\right) \bar{w}\right)} \equiv \Omega\left(p^{*}\right) .
\end{aligned}
$$

Note that $\Omega\left(p^{*}\right) \in[0,1]$, and also that it is a continuous function of $p^{*}$. It follows from Brouwer's fixed point theorem that $\Omega\left(p^{*}\right)$ has a fixed point, which characterizes the equilibrium. Note also that:

$$
\begin{aligned}
& \Omega^{\prime}\left(p^{*}\right)=\frac{\gamma^{\prime}\left(Z_{R}\right) \frac{\partial Z_{R}}{\partial p^{*}}\left(\gamma\left(Z_{R}\right)+\gamma\left(Z_{D}\right)\right)-\gamma\left(\gamma^{\prime}\left(Z_{R}\right) \frac{\partial Z_{R}}{\partial p^{*}}+\gamma^{\prime}\left(Z_{D}\right) \frac{\partial Z_{D}}{\partial p^{*}}\right)}{\left[\gamma\left(Z_{R}\right)+\gamma\left(Z_{D}\right)\right]^{2}} \\
& \propto \gamma\left(Z_{D}\right) \gamma^{\prime}\left(Z_{R}\right) \frac{\partial Z_{R}}{\partial p^{*}}-\gamma\left(Z_{R}\right) \gamma^{\prime}\left(Z_{D}\right) \frac{\partial Z_{D}}{\partial p^{*}}= \\
&=-\left[\gamma\left(Z_{D}\right) \gamma^{\prime}\left(Z_{R}\right)+\gamma\left(Z_{R}\right) \gamma^{\prime}\left(Z_{D}\right)\right](1-\sigma) \lambda\left(1-p^{*}\right)^{-\sigma} \bar{w}<0 .
\end{aligned}
$$

It thus follows that this fixed point is unique.

\section{Proof Proposition 2.}

1. If $\gamma^{\prime}(\cdot)=0$ everywhere, meaning that contributions do not affect turnout, then (12) will imply that:

$$
p^{*}=\frac{\gamma}{\gamma+\gamma}=\frac{1}{2}
$$


2. Using (13), one can compute:

$$
\begin{aligned}
\frac{\partial \tau}{\partial \sigma} & =\left[\left(1-p^{*}\right)^{-\sigma}+(1-\sigma)\left(1-p^{*}\right)^{-\sigma}\left(\log \left(1-p^{*}\right)-\sigma \frac{\frac{\partial p^{*}}{\partial \sigma}}{1-p^{*}}\right)\right]= \\
& =\left(1-p^{*}\right)^{-\sigma}\left[\left(1+(1-\sigma) \log \left(1-p^{*}\right)\right)-\frac{(1-\sigma) \sigma}{\left(1-p^{*}\right)} \frac{\partial p^{*}}{\partial \sigma}\right]
\end{aligned}
$$

The last term in square brackets is obviously equal to zero, given part (i) above. The term $\left(1+(1-\sigma) \log \left(1-p^{*}\right)\right)$ is equal to $1-(1-\sigma)$ $\log 2>0$, hence $\frac{\partial \tau}{\partial \sigma}>0$.

Proof Proposition 3. Suppose $p^{*} \leq \frac{1}{2}$. It follows from (12) and $\gamma^{\prime}(\cdot)>$ 0 that $Z_{R} \leq Z_{D}$. This in turn requires:

$$
\left(1-p^{*}\right)^{1-\sigma} \leq \frac{1}{2} \Rightarrow p^{*} \geq 1-\left(\frac{1}{2}\right)^{\frac{1}{1-\sigma}}>\frac{1}{2}
$$

where the last inequality follows from the fact that $1-\left(\frac{1}{2}\right)^{\frac{1}{1-\sigma}}$ is monotonically increasing in $\sigma$, and $\lim _{\sigma \rightarrow 0} 1-\left(\frac{1}{2}\right)^{\frac{1}{1-\sigma}}=\frac{1}{2}$. This contradiction establishes the result.

Proof Proposition 4. Consider (19), as we momentarily disregard the possibility of a corner solution in which $p^{*}>\bar{p}(\sigma) \equiv 1-(1-\sigma)^{\frac{1}{\sigma}}$ and $\tau=0$. One needs to sign $\frac{\partial p^{*}}{\partial \sigma}$ in order to figure out the behavior of $\frac{\partial \tau}{\partial \sigma}$. Given (12 ), and using the implicit function theorem, it follows that:

$\frac{\partial p^{*}}{\partial \sigma}=\frac{-\lambda \bar{w}\left(1-p^{*}\right)^{1-\sigma} \log \left(1-p^{*}\right)\left[\gamma^{\prime}\left(Z_{R}\right)\left(1-p^{*}\right)+\gamma^{\prime}\left(Z_{D}\right) p^{*}\right]}{\gamma\left(Z_{R}\right)+\gamma\left(Z_{D}\right)+\lambda \bar{w}(1-\sigma)\left(1-p^{*}\right)^{-\sigma}\left[\gamma^{\prime}\left(Z_{R}\right)\left(1-p^{*}\right)+\gamma^{\prime}\left(Z_{D}\right) p^{*}\right]}$.

The key term is the one in square brackets, which is clearly positive. This means that the numerator is positive, since $\log \left(1-p^{*}\right)<0$. Similarly, one can conclude that the denominator is positive. As a result, we have $\frac{\partial p^{*}}{\partial \sigma}>0$ : an increase in inequality unambiguously leads to the decisive agent being at a higher position in the wealth distribution. We can also rewrite:

$\frac{\partial p^{*}}{\partial \sigma}=\frac{-\left(1-p^{*}\right) \log \left(1-p^{*}\right) A}{(1-\sigma) A+B}$

where $A \equiv \lambda \bar{w}\left(1-p^{*}\right)^{-\sigma}\left[\gamma^{\prime}\left(Z_{R}\right)\left(1-p^{*}\right)+\gamma^{\prime}\left(Z_{D}\right) p^{*}\right]$, and $B \equiv \gamma\left(Z_{R}\right)+$ $\gamma\left(Z_{D}\right)$

We can now use this back in (19). There are two terms in square brackets, which correspond to two separate effects: the term $\left(1+(1-\sigma) \log \left(1-p^{*}\right)\right)$ corresponds to the change in the preferred rate of the indifferent agent, keeping the identity of this agent fixed. This could be called an "indifferent voter's preference effect": Inequality affects the desire for redistribution of any given indifferent agent. Note that this term will be positive if $p^{*}$ is sufficiently small: a sufficiently poor agent will always have her desire for redistribution increased by inequality. (In particular, this will always be the case for the median agent, as shown in Proposition 2.) However, it can be negative if $p^{*}$ is sufficiently large. The second term, $-\frac{(1-\sigma) \sigma}{\left(1-p^{*}\right)} \frac{\partial p^{*}}{\partial \sigma}$, will be negative, as argued above. This corresponds to an "endogenous indifferent voter" effect, given by the effect of inequality, by increasing the amount of contributions from the rich relative to those from the poor, in leading to the indifferent agent being an individual at a higher percentile, who is thus less keen on redistribution. Combining the endogenous indifferent voter effect and the possibility that the indifferent voter's preference effect be negative, it is possible that $\frac{\partial \tau}{\partial \sigma}$ be negative.

To see how (19) will behave when both the "indifferent voter's preference" and the "endogenous indifferent voter" effects interact, note that we can rewrite it as:

$$
\begin{aligned}
\frac{\partial \tau}{\partial \sigma} & =\left(1-p^{*}\right)^{-\sigma}\left[\left(1+(1-\sigma) \log \left(1-p^{*}\right)\right)+\frac{(1-\sigma) \sigma}{\left(1-p^{*}\right)} \frac{\left(1-p^{*}\right) \log \left(1-p^{*}\right) A}{(1-\sigma) A+B}\right]= \\
& =\left(1-p^{*}\right)^{-\sigma}\left[1+(1-\sigma) \log \left(1-p^{*}\right)\left(1+\frac{\sigma A}{(1-\sigma) A+B}\right)\right]= \\
& =\left(1-p^{*}\right)^{-\sigma}\left[1+(1-\sigma) \log \left(1-p^{*}\right) \frac{A+B}{(1-\sigma) A+B}\right] .
\end{aligned}
$$

If we let $A \rightarrow \infty$, the term in square brackets will converge to $1+$ $\log \left(1-p^{*}\right)$. Using $Z_{R}$ as described by (8), we can rewrite $A=$

$\frac{1}{\left(1-p^{*}\right)} Z_{R}\left[\gamma^{\prime}\left(Z_{R}\right)\left(1-p^{*}\right)+\gamma^{\prime}\left(Z_{D}\right) p^{*}\right]$; if $\lim _{Z \rightarrow \infty}\left(Z \gamma^{\prime}(Z)\right)=\infty-$ i.e. if $\gamma^{\prime}(Z)$ goes to zero sufficiently slowly, we can let $A$ grow without bound by increasing $\bar{w}$. (Note that, by choosing units, we are essentially free to increase $\bar{w}$ arbitrarily.) Under such conditions, the behavior of $\frac{\partial \tau}{\partial \sigma}$ will be determined by the behavior of $1+\log \left(1-p^{*}\right)$.

Now consider the situation in which $\sigma \rightarrow 1$. This is a situation of "perfect inequality", where all wealth is held by a single (zero-measure) individual who obviously favors Party $R$ against redistribution. In fact, $\sigma \rightarrow 1$ implies $Z_{D} \rightarrow 0$ and $Z_{R} \rightarrow \lambda \bar{w}$; since we denote $\lim _{Z \rightarrow 0} \gamma(Z)=\varepsilon$, it follows that $\lim _{\sigma \rightarrow 1} p^{*}=\frac{\gamma(\lambda \bar{w})}{\gamma(\lambda \bar{w})+\varepsilon}$, which gets arbitrarily close to 1 as $\varepsilon$ gets arbitrarily small. It is also straightforward to see that $\lim _{\sigma \rightarrow 0} p^{*}=\frac{1}{2}$, since when all individuals are equal there is no incentive to deviate from the median to obtain contributions. It suffices to note that $\sigma \rightarrow 0$ implies $Z_{D} \rightarrow p^{*} \lambda \bar{w}$ and $Z_{R} \rightarrow\left(1-p^{*}\right) \lambda \bar{w}$, and that with those values it will be the case that $p^{*}=\frac{1}{2}$ will satisfy the equilibrium condition. In addition, we have shown that $\frac{\partial p^{*}}{\partial \sigma}>0$. Putting all of this together, we conclude that $\lim _{\sigma \rightarrow 0} \frac{\partial \tau}{\partial \sigma} \propto 1-\log (2)>0, \lim _{\sigma \rightarrow 1} \frac{\partial \tau}{\partial \sigma}<0$, and $\frac{\partial^{2} \tau}{\partial \sigma^{2}}<0$ for all $\sigma \in(0,1)$. This in turn means that there exists a $\bar{\sigma}$ such that $\frac{\partial \tau}{\partial \sigma}>0$ if and only if $\sigma<\bar{\sigma}$. Finally, note that, from (13), we have $\lim _{\sigma \rightarrow 0} \tau=\lim _{\sigma \rightarrow 1} \tau=0$. Given the results above concerning the behavior of $\lim _{\sigma \rightarrow 0} \frac{\partial \tau}{\partial \sigma}, \lim _{\sigma \rightarrow 1} \frac{\partial \tau}{\partial \sigma}$, and $\frac{\partial^{2} \tau}{\partial \sigma^{2}}$, these imply that $\tau>0$ for all $\sigma \in(0,1)$. In other words, we have $p^{*}<\bar{p}(\sigma)$ for all $\sigma \in(0,1)$, and there is no corner solution in this case. This completes the proof.

Proof Corollary 1. Totally differentiating (12) with respect to $\sigma$ we obtain:

$$
-\gamma\left(Z_{R}\right) \frac{\partial p^{*}}{\partial \sigma}+\left(1-p^{*}\right) \gamma^{\prime}\left(Z_{R}\right) \frac{\partial Z_{R}}{\partial \sigma}=\gamma\left(Z_{D}\right) \frac{\partial p^{*}}{\partial \sigma}+p^{*} \gamma^{\prime}\left(Z_{D}\right) \frac{\partial Z_{D}}{\partial \sigma} .
$$

From (7) and (8), it is easy to see that $\frac{\partial Z_{R}}{\partial \sigma}=-\frac{\partial Z_{D}}{\partial \sigma}$, hence:

$\left(\gamma\left(Z_{D}\right)+\gamma\left(Z_{R}\right)\right) \frac{\partial p^{*}}{\partial \sigma}=\left[\left(1-p^{*}\right) \gamma^{\prime}\left(Z_{R}\right)+p^{*} \gamma^{\prime}\left(Z_{D}\right)\right] \frac{\partial Z_{R}}{\partial \sigma}$. 
It follows that the sign of $\frac{\partial Z_{R}}{\partial \sigma}$ will be the same as that of $\frac{\partial p^{*}}{\partial \sigma}$, while the opposite holds for $\frac{\partial Z_{D}}{\partial \sigma}$. Since under the conditions of Proposition 4 we have $\frac{\partial p^{*}}{\partial \sigma}>0$, the result immediately follows.

\section{County-level inequality and contributions}

Let us analyze the impact of changes in inequality on the amount of contributions for both parties at the county level, which are described by $Z_{R}^{k}=\lambda \frac{1}{1-\sigma_{k}}\left(\frac{w_{k, \min }}{w_{p^{\star}}}\right)^{\frac{1}{\sigma_{k}}} w_{p^{\star}}$ and $Z_{D}^{k}=\lambda \frac{w_{k, \min }}{1-\sigma_{k}}-\lambda Z_{R}^{k}$. It follows

$\frac{\partial Z_{R}^{k}}{\partial \sigma_{k}} \propto \frac{1}{\left(1-\sigma_{k}\right)^{2}}\left(\frac{w_{k, \min }}{w_{p^{*}}}\right)^{\frac{1}{\sigma_{k}}}-\frac{1}{\sigma_{k}^{2}} \frac{1}{\left(1-\sigma_{k}\right)}\left(\frac{w_{k, \min }}{w_{p^{*}}}\right)^{\frac{1}{\sigma_{k}}} \log \left(\frac{w_{k, \min }}{w_{p^{*}}}\right)$.

This expression is unambiguously positive as long as $w_{k, \min }<w_{p^{*}}$. It is easy to see that $\frac{\partial Z_{D}^{k}}{\partial \sigma_{k}} \propto \frac{w_{k, m i n}}{\left(1-\sigma_{k}\right)^{2}}-\frac{\partial Z_{R}^{k}}{\partial \sigma_{k}}$, so that it has the opposite sign of $\frac{\partial Z_{R}^{k}}{\partial \sigma_{k}}$ unless $w_{k, \min }$ is large. It is interesting to understand the intuition for the term $\frac{w_{k, \min }}{\left(1-\sigma_{k}\right)^{2}}$, which comes from the fact that an increase in inequality affects the mean of the distribution, and hence has a positive impact on contributions even to Party $D$. An alternative specification would be to maintain the assumption of a constant mean at $\bar{w}_{k}$, and let the minimum wealth parameter vary according to $w_{k, \min } \equiv\left(1-\sigma_{k}\right) \bar{w}_{k}$. The basic message would be essentially the same, except that the positive impact on $Z_{R}^{k}$ would be counteracted by a term on $-\log \left(\frac{\bar{w}_{k}}{w_{p^{\star}}}\right)$, which could be negative if $\bar{w}_{k}$ is very high. (The converse intuition is that an increase in inequality would decrease the minimum level of wealth, and this shift in the distribution would reduce the number of individuals contributing to Party $R$.)

\section{References}

Alesina, Alesina, Rodrik, Dani, 1994. Distributive politics and economic growth. Quarterly Journal of Economics 109, 465-490.

Alesina, Alberto, Rosenthal, Howard, 1995. Partisan Politics, Divided Government and the Economy. Cambridge University Press, Cambridge, UK.

Ansolabehere, Stephen, 2007. Cooperative Congressional Election Study, 2006: Common Content. Release 2: November 14, 2007. Available on M.I.T, Cambridge, MAhttp://web.mit.edu/polisci/portl/cces/commoncontent.html.

Ansolabehere, Stephen, de Figueiredo, John M., Snyder Jr., James M., 2003. Why is there so little money in U.S. politics? The Journal of Economic Perspectives 17, 105-130.

Ansolabehere, Stephen, Snyder Jr., James M., 2000. Soft money, hard money, strong parties. Columbia Law Review 100, 598-619.

Austen-Smith, David, 1987. Interest groups, campaign contributions, and probabilistic voting. Public Choice 54, 123-139.

Bénabou, Roland, 1996. Inequality and Growth. In: Bernanke, Ben, Rotemberg, Julio (Eds.), NBER Macroeconomics Annual 1996. MIT Press, Cambridge, MA.

Bénabou, Roland, 2000. Unequal societies: income distribution and the social contract. The American Economic Review 90, 96-129.

Bergan, Daniel E., Gerber, Alan S., Green, Donald P., Panagopoulos, Costas, 2005. Grassroots mobilization and voter turnout in 2004. Public Opinion Quarterly 69, 760-777.
Bolton, Patrick, Roland, Gerard, 1997. The breakup of nations. Quarterly Journal of Economics 112, 1057-1090.

Calvert, Randall L., 1985. Robustness of the multidimensional voting model: candidate motivations, uncertainty, and convergence. American Journal of Political Science 29, 69-95.

Campante, Filipe, 2007. Redistribution in a Model of Voting and Campaign Contributions. Harvard Kennedy School Faculty Research Working Paper Series RWP07-045.

Chamon, Marcos and Ethan Kaplan (2007), "The Iceberg Theory of Campaign Contributions: Political Threats and Interest Group Behavior", IIES (unpublished).

Coate, Stephen, 2004. Political competition with campaign contributions and informative advertising. Journal of the European Economic Association 2, 772-804.

Downs, Anthony, 1957. An Economic Theory of Democracy. Harper and Row, New York.

Gerber, Alan S., 2004. Does campaign spending work? Field experiments provide evidence and suggest new theory. The American Behavioral Scientist 47, 541-574

Gimpel, James G., Lee, Frances E., Kaminski, Joshua, 2006. The political geography of campaign contributions in American politics. Journal of Politics 68, 626-639.

Glaeser, Edward L., 2006. Inequality. In: Weingast, Barry R., Wittman, Donald A. (Eds.), The Oxford Handbook of Political Economy. Oxford University Press, Oxford.

Grossman, Gene M., Helpman, Elhanan, 1996. Electoral competition and special interest policies. Review of Economic Studies 63, 265-286.

Iversen, Torben, Soskice, David, 2006. Electoral institutions and the politics of coalitions: why some democracies redistribute more than others. American Political Science Review 100, 165-181.

Kramer, Gerald H., 1970. The effects of precinct-level canvassing on voter behavior. Public Opinion Quarterly 34, 560-572.

Larcinese, Valentino, 2005. Electoral competition and redistribution with rationally informed voters. Contributions to Economic Analysis and Policy 4 (1) Article $4 .$.

Lee, Woojin, Roemer, John E., 2005. The rise and fall of unionised labour markets: a political economy approach. The Economic Journal 115, 1-40.

Levy, Moshe, Levy, Haim, 2003. Investment talent and the pareto wealth distribution: theoretical and experimental analysis. The Review of Economics and Statistics 85, 709-725.

Lijphart, Arend, 1997. Unequal participation: democracy's unresolved dilemma American Political Science Review 91, 1-14

Mattozzi, Andrea, 2005. Policy uncertainty, electoral securities and redistribution. Caltech Social Science WP 1229 July 2005.

McCarty, Nolan, Poole, Keith T., Rosenthal, Howard, 2006. Polarized America: The Dance of Ideology and Unequal Riches. MIT Press, Cambridge, MA.

Meltzer, Allan H., Richard, Scott F., 1981. A rational theory of the size of government Journal of Political Economy 89, 914-927.

Meltzer, Allan H., Richard, Scott F., 1983. Tests of a rational theory of the size of government. Public Choice 41, 403-418.

Milanovic, Branko, 2000. The median-voter hypothesis, income inequality, and income redistribution: an empirical test with the required data. European Journal of Political Economy 16, 367-410.

Perotti, Roberto, 1996. Inequality, redistribution and growth: what the data say. Journal of Economic Growth 1, 755-776.

Persson, Torsten, Tabellini, Guido, 1994. Is inequality harmful for growth? The American Economic Review 84, 600-621.

Persson, Torsten, Tabellini, Guido, 2000. Political Economics. MIT Press, Cambridge, MA.

Prat, Andrea, 2002. Campaign spending with office-seeking politicians, rational voters, and multiple lobbies. Journal of Economic Theory 103, 162-189.

Roberts, Kevin, 1977. Voting over income tax schedules. Journal of Public Economics 8 , 329-340.

Rodríguez, Francisco, 2004. Inequality, redistribution, and rent-seeking. Economics \& Politics 16, 287-320.

Roemer, John E., 1998. Why the poor do not expropriate the rich: an old argument in a new garb. Journal of Public Economics 70, 399-424.

Roemer, John E., 2006. Party competition under private and public financing: A comparison of institutions. Advances in Theoretical Economics 6 (1) Article 2

Romer, Thomas, 1975. Individual welfare, majority voting and the properties of a linear income tax. Journal of Public Economics 7, 163-185.

Rosenstone, Steven J., Hansen, John Mark, 1996. Mobilization, Participation, and Democracy in America, 1st ed 1993. Longman, New York.

Verba, Sidney, Nie, Norman H., Kim, Jae-On, 1978. Participation and Political Equality: A Seven-Nation Comparison. Cambridge University Press, Cambridge, UK. 